\title{
Analysis of Electron Delocalization in Aromatic Systems: Individual Molecular Orbital Contributions to Para-Delocalization Indexes (PDI)
}

\author{
Mireia Güellr ${ }^{\Upsilon}$ Eduard Matito ${ }^{\Upsilon}$, Josep M. Luis ${ }^{\Upsilon}$, Jordi Poater ${ }^{\S}$ and Miquel Solàr,* \\ Institut de Química Computacional and Departament de Química, Universitat de \\ Girona, Campus de Montilivi, 17071 Girona, Catalonia, Spain, Afdeling Theoretische \\ Chemie, Scheikundig Laboratorium der Vrije Universiteit, De Boelelaan 1083, NL-1081 \\ HV Amsterdam, The Netherlands.$$
\text { miquel.sola@udg.es }
$$

\begin{abstract}
Our research group has recently defined two new aromaticity indexes based on the analysis of electron delocalization in aromatic species using the quantum theory of atoms-in-molecules. One of these indexes is the para-delocalization index (PDI) that measures the electronic delocalization between para-related carbon atoms in sixmembered rings. In this paper, we show that this index can be partitioned into individual molecular orbital contributions. We have applied this PDI decomposition to several polycyclic aromatic hydrocarbons showing that this partitioning provides new insight into the origin of aromaticity.
\end{abstract}

Keywords: Delocalization index, aromaticity, para-delocalization index (PDI), atomsin-molecules (AIM), molecular orbital contributions, $\sigma$ and $\pi$ separation.

\footnotetext{
* To whom correspondence should be addressed. Phone: +34-972.418.912. Fax: +34-972.418.356.

${ }^{\Upsilon}$ Institut de Química Computacional and Departament de Química, Universitat de Girona.

$\S$ Afdeling Theoretische Chemie, Vrije Universiteit.
} 


\section{Introduction}

The concept of aromaticity is of central importance for the interpretation of molecular structure, stability, reactivity, and magnetic properties of many organic and inorganic compounds. ${ }^{1,2}$ Aromaticity is not an observable and consequently it has no precise quantitative definition and is not directly measurable experimentally. The imprecise nature of aromaticity has stimulated the quest for quantitative definitions, although nearly everyone would agree that there is not a well-established method to quantify the aromatic character of molecules yet. The evaluation of aromaticity is usually done indirectly by measuring some physicochemical property that reflects the aromatic character of molecules. Thus, most aromaticity indicators are based on the classical aromaticity criteria, namely, structural, magnetic, energetic, and reactivitybased measures. ${ }^{2,3}$ Undoubtedly, the origin of the aromatic properties is the cyclic delocalized distribution of $\pi$-electrons. For this reason, more recently, new ways to quantify the aromaticity based on the measure of electronic delocalization in aromatic molecules have been devised (for a recent review see reference 4). In particular, two new indexes based on the calculation of delocalization indexes (DIs) in the framework of the quantum theory of atoms-in-molecules (QTAIM) have been recently defined by some of us: the para-delocalization index (PDI) $)^{5}$ and the aromatic fluctuation index (FLU). ${ }^{6}$ In this context it is worth mentioning the work of Matta et al. ${ }^{7}$ who also attempted to construct an HOMA-like index ${ }^{8}$ from QTAIM by substituting the bond length by the total electron delocalization and also the use by Giambiagi et al. ${ }^{9}$ and Bultinck et al. ${ }^{10}$ of n-center electron DIs as descriptors of aromaticity.

In the continual drive to reach a wider understanding of aromaticity, some 
aromaticity measures have been separated into their $\sigma$ and $\pi$ contributions in planar systems. This goal has been achieved for a series of indicators of aromaticity, namely, ring currents, ${ }^{15}$ nucleus-independent chemical shifts (NICS), ${ }^{16,17}$ electron localization function (ELF), ${ }^{18}$ and aromatic stabilization energies (ASE). ${ }^{19}$ Less common is the separation of aromaticity indexes into individual molecular orbital (MO) contributions in MO-based methods, although successful experiences have been reported for NICS $^{17,20,21}$ and ring currents. ${ }^{22-25}$ The aim of the present work is to show that PDI can also be separated into individual MO contributions and, in the particular case of planar systems, into its $\sigma$ and $\pi$ contributions. Results for a series of polycyclic aromatic hydrocarbons (PAHs) are presented and compared when possible with results from MOdissected NICS and ring currents.

\section{Theoretical basis of the analysis}

In 1996, Bader and coworkers ${ }^{26}$ reported in a seminal work that the electron delocalization in benzene was greater for para-related carbon atoms (para-DI) than for meta-related ones (meta-DI). Later on, some of $\mathrm{us}^{5}$ defined the para-delocalization index (PDI) as the averaged of para-DI in six-membered rings (6-MRs) and used this index as a measure of local aromaticity. The PDI is a specific measure of local aromaticity for 6-MRs, where three para-related positions exist, namely, $(1,4),(2,5)$, and $(3,6)$. By definition, the PDI of a 6-MR is given by:

$$
P D I=\frac{\delta(1,4)+\delta(2,5)+\delta(3,6)}{3},
$$

In Eq. (1), $\delta(A, B)$, the DI, is derived from the double integration of the exchangecorrelation density over the atomic basins defined within the QTAIM theory: ${ }^{27}$ 


$$
\delta(A, B)=-2 \iint_{A} \Gamma_{x c}\left(\vec{r}_{1}, \vec{r}_{2}\right) d \vec{r}_{1} d \vec{r}_{2}
$$

The term $\delta(A, B)$ gives a quantitative measure of the number of electrons delocalized or shared between atomic basins $A$ and $B$.

For closed-shell molecules and for single determinant wave functions, Eq. (2) is simplified to: ${ }^{27}$

$$
\delta(A, B)=2 \sum_{i, j} S_{i j}(A) S_{i j}(B)
$$

where the summations run over all the occupied molecular spin-orbitals and $S_{i j}(A)$ is the overlap between occupied molecular spin-orbitals $i$ and $j$ over the basin of atom $A$.

In molecules having a plane of symmetry, the orbitals can be classified as $\sigma$ or $\pi$, depending on their symmetric or antisymmetric behavior with respect to reflection in the plane. Because the QTAIM partition of space preserves the symmetry of the system, the overlap integrals $S_{i j}(A)$ vanish when $i$ and $j$ belong to different sets, and consequently, the contributions of $\sigma$ and $\pi$ electrons to the DIs can be exactly separated. In this case it is also possible to define the $\pi$ contribution to the PDI using the $\pi$ component of the DIs between para-related carbon atoms in 6-MRs as:

$$
P D I_{\pi}=\frac{\delta_{\pi}(1,4)+\delta_{\pi}(2,5)+\delta_{\pi}(3,6)}{3} .
$$

Finally, Eq. (4) can also be written as:

$$
\delta(A, B)=\sum_{i} 2 \sum_{j} S_{i j}(A) S_{i j}(B)=\sum_{i} \delta_{i}(A, B)
$$


where $\delta_{i}(A, B)$ gives the contribution of the $i$ orbital to the total $\delta(A, B)$. Thus, for monodeterminantal wave functions, the DI can be separated into its individual MO contributions and, in particular, the PDI can also be split up into MO components as:

$$
P D I_{i}=\frac{\delta_{i}(1,4)+\delta_{i}(2,5)+\delta_{i}(3,6)}{3}
$$

with:

$$
P D I=\sum_{i} P D I_{i}=\sum_{i} \frac{\delta_{i}(1,4)+\delta_{i}(2,5)+\delta_{i}(3,6)}{3} .
$$

One can also define analogously the $\mathrm{PDI}_{\pi, i}$ as the contribution to $\mathrm{PDI}_{\pi}$ of the $i \pi$-orbital. While total $\delta(A, B)$ or $\delta_{\pi}(A, B)$ are always positive, the components $\delta_{i}(A, B)$ or $\delta_{\pi, i}(A, B)$ can be positive or negative depending on the overlaps between $i$ and $j$ orbitals in the basins of atoms $\mathrm{A}$ and $\mathrm{B} . \delta_{i}(A, B)$ is negative when the two electrons occupying orbital $i$ cause a greater localization of the rest of the electrons in the molecule, and, therefore produce a reduction in the total electronic delocalization.

\section{Computational Details}

Geometries of all PAHs in their ground states have been fully optimized with the hybrid density functional theory (DFT) B3LYP method ${ }^{28}$ using the 6-311G(d,p) basis set by means of the Gaussian 03 program. ${ }^{29}$ Integrations of DIs needed to calculate the PDIs have been performed using the AIMPAC collection of programs. ${ }^{30}$ Calculation of these DIs at the DFT level of theory cannot be performed exactly ${ }^{31}$ because the electronpair density is not available at this level of theory. As an approximation, we have used the Kohn-Sham orbitals obtained from DFT to calculate Hartree-Fock-like DIs using Eq. (5). ${ }^{31}$ The numerical accuracy of the AIM calculations has been assessed using two 
criteria: i) The integration of the Laplacian of the electron density $\left(\nabla^{2} \rho(\mathbf{r})\right)$ within an atomic basin must be close to zero; ii) The number of electrons in a molecule must be equal to the sum of all the electron populations of a molecule, and also equal to the sum of all the localization indices and half of the delocalization indices in the molecule. ${ }^{32}$ For all atomic calculations, integrated absolute values of $\nabla^{2} \rho(\mathbf{r})$ were always less than 0.001 a.u. For all molecules, errors in the calculated number of electrons were always less than 0.01 a.u.

\section{Results and discussion}

Scheme 1 depicts the eleven PAHs analyzed together with the labels assigned to each different ring. Table 1 contains the values of the PDI and $\mathrm{PDI}_{\pi}$ for all studied rings as well as all individual $\mathrm{MO}$ contributions to $\mathrm{PDI}_{\pi}$ which are certainly the most important contributions to the total PDI. The $\mathrm{PDI}_{\pi}$ contribution to the total PDI ranges from $90 \%$ in the most aromatic 6-MR (benzene) to $69 \%$ for the least aromatic 6-MR of indacene. The $\mathrm{PDI}_{\sigma}$ obtained as the difference between the total PDI and $\mathrm{PDI}_{\pi}$ has values that go from 0.010 e in benzene, pyracyclene, and acenaphthalene to 0.008 e in ring $\mathrm{B}$ of chrysene. So, the $\sigma$ contribution to PDI is relatively small and, more importantly, it is quite constant for all PAHs studied and, therefore, the differences between PDI values come mainly from the $\mathrm{PDI}_{\pi}$ contribution. For this reason, the decomposition into individual MO contributions in Table 1 is only done for the $\mathrm{PDI}_{\pi}$ part of the PDI. The occupied $\pi$-orbitals of the eleven PAHs studied are depicted in Figure 1. 
For the archetypical aromatic molecule, benzene, it is found that the doubly degenerated $\mathrm{e}_{\mathrm{g}} \mathrm{HOMO}$ orbitals are those that have a greater contribution to the PDI. The a2u $\pi$-orbital has a negative contribution of -0.088 e. This means that the two electrons in a2u MO reduce the delocalization between para-related carbon atoms in benzene. This can be understood by simple inspection of the $a_{2 u}$ and $\mathrm{e}_{1 \mathrm{~g}} \pi$-orbitals, which shows that the products $S_{a_{2 u} e_{1 g}}\left(C_{1}\right) S_{a_{2 u} e_{1 g}}\left(C_{4}\right), \quad S_{a_{2 u} e_{1 g}}\left(C_{2}\right) S_{a_{2 u} e_{1 g}}\left(C_{5}\right)$, and $S_{a_{2 u} e_{1 g}}\left(C_{3}\right) S_{a_{2 u} e_{1 g}}\left(C_{6}\right)$ involved in the $\mathrm{PDI}_{\pi, \mathrm{a} 2 \mathrm{u}}$ calculation are always negative or zero. Indeed, the product $S_{i j}(A) S_{i j}(B)$, being A and B para related carbon atoms in a 6-MR, is always negative or zero if the sum of total nodal planes in orbitals $i$ and $j$ gives an even number and positive or zero otherwise. Interestingly, when the two electrons from orbital a2u are removed without reoptimizing the wave function, the $\mathrm{PDI}_{\pi}$ value becomes 0.375 e, which means that the aromaticity of benzene increases by removing these two electrons in the a2u orbital according to PDI values.

Our result for benzene is totally in line with those derived from the analysis of the individual MO contributions to ring currents and dissected-MO NICS. As shown by Steiner and Fowler, an occupied-to-unoccupied e1g(HOMO) $\rightarrow$ ezu(LUMO) translationally allowed transition gives the main diamagnetic contribution to the diatropic ring of benzene. ${ }^{23-25}$ According to this results only the four electrons of the two e1g $\pi$-orbitals contribute significantly to the ring current. ${ }^{23,24}$ As to the NICS studies, although the NICS(0) value of the a2u MO is more negative than that of the two e1g $\pi$ orbitals, ${ }^{17}$ the opposite is true for $\operatorname{NICS}_{\mathrm{zz}}(0)$ (the $\mathrm{zz}$ tensor component of the isotropic 
$\operatorname{NICS}(0)) .{ }^{21}$ Since the ring current density in aromatic compounds is more related to $\operatorname{NICS}_{z z}(0)$ than to NICS(0) itself, ${ }^{33}$ the conclusion from NICS studies is also that the $\mathrm{e}_{1 \mathrm{~g}}$ $\pi$-orbitals are the main responsible of the aromatic behavior in benzene. ${ }^{21}$

In the naphthalene $\pi$-system again only the four electrons in the two highestlying $\mathrm{au}(\mathrm{HOMO})$ and $\mathrm{b} 1 \mathrm{u}(\mathrm{HOMO}-1)$ make significant contributions to the total diamagnetic ring current. ${ }^{24}$ These two orbitals also give important individual MOs contributions to PDI, but in our case the orbital that contributes the most to the PDI is the $\mathrm{b}_{3 \mathrm{~g}}(\mathrm{HOMO}-2)$ owing to the large and positive $S_{a_{u} b_{3 g}}\left(C_{1}\right) S_{a_{u} b_{3 g}}\left(C_{4}\right)$ term. Thus, the three highest-lying MOs of naphthalene contribute positively to the PDI, while the two lowest-lying $\pi$-orbitals have negative contributions, especially the b1u(HOMO-7). Thus, like in benzene, the $\pi$-orbital with a unique nodal plane (the molecular plane) is the one that reduces more significantly the PDI value.

Similarly, for the A ring of anthracene and phenanthrene, the four highestlying occupied $\pi$-orbitals are those that contribute more to the PDI, while involvement of the three lowest-lying $\pi$-orbitals is negative or close to zero. Contributions of the four highest-lying occupied $\pi$-orbitals to the PDI of phenanthrene are larger, in general, than to anthracene as expected from the large aromatic character of ring A in phenanthrene. ${ }^{13}$ For the $\mathrm{B}$ ring of anthracene the $\mathrm{a}_{\mathrm{u}}(\mathrm{HOMO}-2)$ has a negative contribution, while the $\mathrm{b}_{2 \mathrm{~g}}(\mathrm{HOMO}-8)$ has a positive non-negligible role in the $\pi$-para electronic delocalization. For tetracene and chrysene, the six highest-lying MOs are those that contribute more to the PDI of both rings $\mathrm{A}$ and $\mathrm{B}$, while the three lowest-lying $\pi$-orbitals have a negative contribution, with the only exception of the $\mathrm{b}_{2 \mathrm{~g}}(\mathrm{HOMO}-4)$ and $\mathrm{b}_{1 \mathrm{u}}(\mathrm{HOMO}-9)$ orbitals for the ring $\mathrm{B}$ of tetracene that have small negative and positive contributions to PDI, 
respectively.

As indicated by other aromaticity indexes, ${ }^{34}$ PDI gives also the largest aromaticity to the most external rings A of pyrene and coronene. For these A rings, the largest contributions to PDI come from the six and seven highest-lying occupied $\pi$ orbitals, respectively. In particular, for the ring A of pyrene, the large value assigned to the $a_{u}(\mathrm{HOMO}-3) \pi$-orbital comes mainly from its interaction with the $b_{3 g}(\mathrm{HOMO})$. Interestingly, for the less aromatic ring B of pyrene and coronene, the contributions from the $b_{3 g}$ and $e_{2 u}$ HOMO orbitals, respectively, to the PDI values are negative. Indeed, for coronene, we find, unexpectedly, that the pair of degenerate e2u HOMOs does not have an important participation to the PDIs of rings A and B. This result is in not in line with the orbital contributions to the current density analysis carried out by Steiner and Fowler in coronene. These authors found that both the inner and outer circulations in coronene come mainly from the four electrons in the degenerate $\mathrm{e}_{2 \mathrm{u}}$ HOMO. ${ }^{24}$

Acenaphthalene results from the addition of a fused 5-MR to naphthalene, while a further addition of a 5-MR leads to pyracylene. 5-MR addition decreases the aromaticity of the 6-MRs when going from naphthalene to acenaphthalene, and from this to pyracylene. ${ }^{12}$ Similarly to that found for most 6-MRs, the main contributions to the PDI of the 6-MRs in acenaphthalene originate from the highest-lying $\pi$-orbitals (b1(HOMO,HOMO-2,HOMO-3) and a2(HOMO-1)). For pyracylene, the most important individual MO contributors to PDI are the $\mathrm{b}_{2 \mathrm{~g}}(\mathrm{HOMO}$ and HOMO-8) $\pi$-orbitals and especially the near-degenerate $\mathrm{b}_{1 \mathrm{u}}(\mathrm{HOMO}-1)$ and $\mathrm{a}_{\mathrm{u}}(\mathrm{HOMO}-2) \pi$-MOs. This is consistent with the fact that the electrons placed in these two latter orbitals are the main 
responsible for the diamagnetic electronic circulation around the perimeter of the naphthalenic unit, according to Steiner and Fowler. ${ }^{24}$ Finally, for indacene, with two 5MRs and only one 6-MR, the aromaticity of the 6-MR is rather low and the main contributions to PDI come from the b2g orbitals, specially owing to the positive overlap between orbitals b3g(HOMO-3) and $\mathrm{b}_{2 \mathrm{~g}}(\mathrm{HOMO})$. MO-dissected ring currents also show that the origin of the paratropic ring current of the 6-MR in indacene lies basically in the $\mathrm{b}_{2 \mathrm{~g}}(\mathrm{HOMO}) \rightarrow \mathrm{b}_{1 \mathrm{~g}}(\mathrm{LUMO})$ transition.

\section{Conclusions}

In this work, we have decomposed the para-delocalization index of local aromaticity into its individual molecular orbital components for a series of PAHs. In general, we have found the lowest-lying $\pi$-MOs contribute negatively to the $\mathrm{PDI}_{\pi}$ and the total PDI, while the highest-lying $\pi$-MOs are those that increase more the $\pi$-electronic delocalization between para-related $\mathrm{C}$ atoms. In this sense, those orbitals with a larger number of nodal planes usually have a larger contribution to the para-electronic delocalization that those with a few nodal planes. Indeed, for all systems studied, the $\pi$ orbital with a unique nodal plane (the molecular plane) negatively contributes to the PDI, and in most cases this $\pi$-orbital is the one that reduces more significantly the PDI value. 


\section{Acknowledgments}

Financial help has been furnished by the Spanish MEC Project No. CTQ200508797-C02-01/BQU and by the catalan Departament d'Universitats, Recerca i Societat de la Informació (DURSI) through project No. 2005SGR-00238. M.G. and E.M. thank the MEC for the doctoral fellowships no. AP-2004-4775 and AP2002-0581, respectively. J.P. also acknowledges the DURSI for the postdoctoral fellowship 2004BE00028. We also thank the Centre de Supercomputació de Catalunya (CESCA) for partial funding of computer time. 


\section{References}

(1) P. v. R. Schleyer, Chem. Rev. (Washington, D. C.), 2001, 101, 11151118; P. v. R. Schleyer, Chem. Rev. (Washington, D. C.), 2005, 105, 3433-3435; V. I. Minkin, M. N. Glukhovtsev and B. Y. Simkin, in Aromaticity and Antiaromaticity: Electronic and Structural Aspects; John Wiley \& Sons: New York, 1994; P. J. Garrat, in Aromaticity; John Wiley \& Sons: New York, 1986; A. T. Balaban, Pure \& Appl. Chem., 1980, 52, 1409-1429; D. Lloyd, J. Chem. Inf. Comp. Sci., 1996, 36, 442-447.

(2) T. M. Krygowski, M. K. Cyrañski, Z. Czarnocki, G. Häfelinger and A. R. Katritzky, Tetrahedron, 2000, 56, 1783-1796.

(3) A. R. Katritzky, P. Barczynski, G. Musumarra, D. Pisano and M. Szafran, J. Am. Chem. Soc., 1989, 111, 7-15.

(4) J. Poater, M. Duran, M. Solà and B. Silvi, Chem. Rev., 2005, 105, 39113947.

(5) J. Poater, X. Fradera, M. Duran and M. Solà, Chem. Eur. J., 2003, 9, 400-406.

(6) E. Matito, M. Duran and M. Solà, J. Chem. Phys., 2005, 122, 014109.

(7) C. F. Matta and J. Hernández-Trujillo, J. Phys. Chem. A, 2003, 107, 7496-7504; C. F. Matta and J. Hernández-Trujillo, J. Phys. Chem. A, 2005, 109, 1079810798.

(8) J. Kruszewski and T. M. Krygowski, Tetrahedron Lett., 1972, 13, 38393842; T. M. Krygowski, J. Chem. Inf. Comp. Sci., 1993, 33, 70-78.

(9) M. Giambiagi, M. S. de Giambiagi, C. D. dos Santos and A. P. de Figueiredo, Phys. Chem. Chem. Phys., 2000, 2, 3381-3392; C. G. Bollini, M. Giambiagi, M. S. Giambiagi and A. P. Figueiredo, J. Math. Chem., 2000, 28, 71-81.

(10) P. Bultinck, R. Ponec and S. Van Damme, J. Phys. Org. Chem., 2005, 18, 706-718.

(11) J. Poater, I. García-Cruz, F. Illas and M. Solà, Phys. Chem. Chem. Phys., 2004, 6, 314-318; G. Portella, J. Poater, J. M. Bofill, P. Alemany and M. Solà, J. Org. Chem., 2005, 70, 4560-4560; E. Matito, J. Poater, M. Duran and M. Solà, J. Mol. Struct. (Theochem), 2005, 727, 165-171; J. Poater, J. M. Bofill, P. Alemany and M. Solà, J. Org. Chem., 2006, 71, 1700-1702.

(12) J. Poater, M. Solà, R. G. Viglione and R. Zanasi, J. Org. Chem., 2004, 69, 7537-7542. 
(13) G. Portella, J. Poater, J. M. Bofill, P. Alemany and M. Solà, J. Org. Chem., 2005, 70, 2509-2521.

(14) A. R. Katritzky, M. Karelson, S. Sild, T. M. Krygowski and K. Jug, J. Org. Chem., 1998, 63, 5228-5231; K. Jug and A. M. Köster, J. Phys. Org. Chem., 1991, 4, 163-169; A. R. Katritzky, K. Jug and D. C. Oniciu, Chem. Rev. (Washington, D. C.), 2001, 101, 1421-1449; T. M. Krygowski and M. K. Cyrañski, Chem. Rev. (Washington, D. C.), 2001, 101, 1385-1419; M. K. Cyrañski, T. M. Krygowski, A. R. Katritzky and P. v. R. Schleyer, J. Org. Chem., 2002, 67, 1333-1338.

(15) E. Steiner and P. W. Fowler, Int. J. Quantum Chem., 1996, 60, 609-616; E. Steiner, P. W. Fowler and L. W. Jenneskens, Angew. Chem. Int. Ed., 2001, 40, 362266; E. Steiner, P. W. Fowler, L. W. Jenneskens and R. W. A. Havenith, Eur. J. Org. Chem., 2002, 163-169.

(16) P. v. R. Schleyer, H. J. Jiao, N. J. R. van Eikema Hommes, V. G. Malkin and O. L. Malkina, J. Am. Chem. Soc., 1997, 119, 12669-12670; P. v. R. Schleyer, M. Manoharan, Z. X. Wang, B. Kiran, H. J. Jiao, R. Puchta and N. J. R. van Eikema Hommes, Org. Lett., 2001, 3, 2465-2468.

(17) T. Heine, P. V. Schleyer, C. Corminboeuf, G. Seifert, R. Reviakine and J. Weber, J. Phys. Chem. A, 2003, 107, 6470-6475.

(18) J. C. Santos, W. Tiznado, R. Contreras and P. Fuentealba, J. Chem. Phys., 2004, 120, 1670-1673; J. C. Santos, J. Andres, A. Aizman and P. Fuentealba, J, Chem. Theor. Comput., 2005, 1, 83-86.

(19) G. Hohlneicher, L. Packschies and J. Weber, ChemPhysChem, 2005, 6, 2541-2551.

(20) R. B. King, T. Heine, C. Corminboeuf and P. v. R. Schleyer, J. Am. Chem. Soc., 2004, 126, 430-431.

(21) Z. Chen, C. S. Wannere, C. Corminboeuf, R. Puchta and P. v. R. Schleyer, Chem. Rev., 2005, 105, 3842-3888.

(22) E. Steiner, P. W. Fowler and R. W. A. Havenith, J. Phys. Chem. A, 2002, 106, 7048-7056; E. Steiner, P. W. Fowler, R. G. Viglione and R. Zanasi, Chem. Phys. Lett., 2002, 355, 471-477; A. Soncini, E. Steiner, P. W. Fowler, R. W. A. Havenith and L. W. Jenneskens, Chem. Eur. J., 2003, 9, 2974-2981; P. W. Fowler, C. W. Rees and A. Soncini, J. Am. Chem. Soc., 2004, 126, 11202-11212.

(23) E. Steiner and P. W. Fowler, Chem. Commun., 2001, 2220-2221.

(24) E. Steiner and P. W. Fowler, J. Phys. Chem. A, 2001, 105, 9553-9562. 
(25) A. Soncini, P. W. Fowler and F. Zerbetto, Chem. Phys. Lett., 2005, 405, 136-141.

(26) R. F. W. Bader, A. Streitwieser, A. Neuhaus, K. E. Laidig and P. Speers, J. Am. Chem. Soc., 1996, 118, 4959-4965.

(27) X. Fradera, M. A. Austen and R. F. W. Bader, J. Phys. Chem. A, 1999, 103, 304-314.

(28) A. D. Becke, J. Chem. Phys., 1993, 98, 5648-5652; C. Lee, W. Yang and R. G. Parr, Phys. Rev. B, 1988, 37, 785-789; P. J. Stephens, F. J. Devlin, C. F. Chabalowski and M. J. Frisch, J. Phys. Chem., 1994, 98, 11623-11627.

(29) M. J. Frisch, G. W. Trucks, H. B. Schlegel, G. E. Scuseria, M. A. Robb, J. R. Cheeseman, J. A. Montgomery Jr., T. Vreven, K. N. Kudin, J. C. Burant, J. M. Millam, S. S. Iyengar, J. Tomasi, V. Barone, B. Mennucci, M. Cossi, G. Scalmani, N. Rega, G. A. Petersson, H. Nakatsuji, M. Hada, M. Ehara, K. Toyota, R. Fukuda, J. Hasegawa, M. Ishida, T. Nakajima, Y. Honda, O. Kitao, H. Nakai, M. Klene, X. Li, J. E. Knox, H. P. Hratchian, J. B. Cross, V. Bakken, C. Adamo, J. Jaramillo, R. Gomperts, R. E. Stratmann, O. Yazyev, A. J. Austin, R. Cammi, C. Pomelli, J. W. Ochterski, P. Y. Ayala, K. Morokuma, G. A. Voth, P. Salvador, J. J. Dannenberg, G. Zakrzewski, S. Dapprich, A. D. Daniels, M. C. Strain, O. Farkas, D. K. Malick, A. D. Rabuck, K. Raghavachari, J. B. Foresman, J. V. Ortiz, Q. Cui, A. G. Baboul, S. Clifford, J. Cioslowski, B. B. Stefanov, G. Liu, A. Liashenko, P. Piskorz, I. Komaromi, R. L. Martin, D. J. Fox, T. Keith, M. A. Al-Laham, C. Y. Peng, A. Nanayakkara, M. Challacombe, P. M. W. Gill, B. Johnson, W. Chen, M. W. Wong, C. Gonzalez and J. A. Pople; Gaussian 03, Revison C.01 ed.; Gaussian, Inc.: Pittsburgh, PA, 2003.

(30) F. W. Biegler-König, R. F. W. Bader and T.-H. Tang, J. Comput. Chem., 1982, 3, 317 (http://www.chemistry.mcmaster.ca/aimpac/).

(31) J. Poater, M. Solà, M. Duran and X. Fradera, Theor. Chem. Acc., 2002, 107, 362-371.

(32) X. Fradera, J. Poater, S. Simon, M. Duran and M. Solà, Theor. Chem. Acc., 2002, 108, 214-224.

(33) C. Corminboeuf, T. Heine, G. Seifert, P. v. R. Schleyer and J. Weber, Phys. Chem. Chem. Phys., 2004, 6, 273-276.

(34) M. Güell, J. Poater, J. M. Luis, O. Mó, M. Yáñez and M. Solà, ChemPhysChem, 2005, 6, 2552-2561. 


\section{Figure Captions}

Scheme 1. Schematic representation of the molecules studied together with ring labels.

Figure 1. Occupied $\pi$ molecular orbitals of (a) benzene, (b) naphthalene, (c) anthracene, (d) phenanthrene, (e) tetracene, (f) chrysene, (g) pyrene, (h) coronene, (i) acenaphthalene, $(\mathrm{j})$ pyracylene, and $(\mathrm{k})$ indacene. Isosurface values are -0.05 and 0.05 a.u. The z-axis contains energies in hartrees. 
Table 1. PDI and $\mathrm{PDI}_{\pi}$ for all studied rings as well as all individual molecular orbital contributions to $\mathrm{PDI}_{\pi}$. Units are electrons.

\begin{tabular}{|c|c|c|c|c|c|}
\hline \multirow[t]{2}{*}{ Molecule } & \multirow[t]{2}{*}{ "Symmetry } & \multirow[t]{2}{*}{ Label } & \multirow[t]{2}{*}{ Orbitals } & \multicolumn{2}{|c|}{ PDI contributions } \\
\hline & & & & A & B \\
\hline \multirow[t]{4}{*}{ Benzene } & $\mathrm{D}_{6 \mathrm{~h}}$ & M1 & $\mathrm{a}_{2 \mathrm{u}}(17)$ & $-0,0880$ & \\
\hline & & & $e_{1 g}(20,21)$ & 0,1813 & \\
\hline & & & $\mathrm{PDI}_{\pi}$ & 0,0933 & \\
\hline & & & PDI & 0,1034 & \\
\hline \multirow[t]{7}{*}{ Naphthalene } & $D_{2 h}$ & M2 & $\mathrm{b}_{1 \mathrm{u}}(27)$ & $-0,0445$ & \\
\hline & & & $b_{2 g}(31)$ & $-0,0120$ & \\
\hline & & & $b_{3 g}(32)$ & 0,0459 & \\
\hline & & & $\mathrm{b}_{1 \mathrm{u}}(33)$ & 0,0452 & \\
\hline & & & $a_{u}(34)$ & 0,0311 & \\
\hline & & & $\mathrm{PDI}_{\pi}$ & 0,0656 & \\
\hline & & & PDI & 0,0749 & \\
\hline \multirow[t]{9}{*}{ Anthracene } & $\mathrm{D}_{2 \mathrm{~h}}$ & M3 & $\mathrm{b}_{1 \mathrm{u}}(36)$ & $-0,0210$ & $-0,0450$ \\
\hline & & & $b_{2 g}(39)$ & $-0,0327$ & 0,0153 \\
\hline & & & $b_{1 u}(43)$ & 0,0103 & $-0,0183$ \\
\hline & & & $b_{3 g}(44)$ & 0,0213 & 0,0480 \\
\hline & & & $a_{u}(45)$ & 0,0390 & $-0,0087$ \\
\hline & & & $b_{2 g}(46)$ & 0,0273 & 0,0293 \\
\hline & & & $b_{3 g}(47)$ & 0,0113 & 0,0347 \\
\hline & & & $\mathrm{PDI}_{\pi}$ & 0,0557 & 0,0553 \\
\hline & & & PDI & 0,0655 & 0,0652 \\
\hline \multirow[t]{9}{*}{ Phenanthrene } & $\mathrm{C}_{2 \mathrm{v}}$ & M4 & $\mathrm{b}_{1}(36)$ & $-0,0273$ & $-0,0347$ \\
\hline & & & $\mathrm{a}_{2}(40)$ & $-0,0353$ & 0,0127 \\
\hline & & & $b_{1}(43)$ & 0,0070 & 0,0050 \\
\hline & & & $b_{1}(44)$ & 0,0347 & 0,0110 \\
\hline & & & $a_{2}(45)$ & 0,0367 & 0,0140 \\
\hline & & & $\mathrm{a}_{2}(46)$ & 0,0350 & 0,0133 \\
\hline & & & $b_{1}(47)$ & 0,0210 & 0,0157 \\
\hline & & & $\mathrm{PDI}_{\pi}$ & 0,0717 & 0,0370 \\
\hline & & & PDI & 0,0812 & 0,0465 \\
\hline
\end{tabular}




\begin{tabular}{|c|c|c|c|c|c|}
\hline \multirow[t]{11}{*}{ Tetracene } & \multirow[t]{11}{*}{$\mathrm{D}_{2 \mathrm{~h}}$} & \multirow[t]{11}{*}{ M5 } & $\mathrm{b}_{1 \mathrm{u}}(46)$ & $-0,0112$ & $-0,0315$ \\
\hline & & & $b_{2 g}(48)$ & $-0,0262$ & $-0,0042$ \\
\hline & & & $\mathrm{b}_{1 \mathrm{u}}(51)$ & $-0,0151$ & 0,0018 \\
\hline & & & $b_{3 g}(55)$ & 0,0114 & 0,0344 \\
\hline & & & $b_{2 g}(56)$ & 0,0154 & $-0,0080$ \\
\hline & & & $a_{u}(57)$ & 0,0292 & 0,0088 \\
\hline & & & b1u(58) & 0,0191 & 0,0212 \\
\hline & & & $b_{39}(59)$ & 0,0253 & 0,0050 \\
\hline & & & $\mathrm{au}_{\mathrm{u}}(60)$ & 0,0040 & 0,0252 \\
\hline & & & $\mathrm{PDI}_{\pi}$ & 0,0519 & 0,0527 \\
\hline & & & PDI & 0,0611 & 0,0614 \\
\hline \multirow[t]{11}{*}{ Chrysene } & \multirow[t]{11}{*}{$\mathrm{C}_{2 \mathrm{~h}}$} & \multirow[t]{11}{*}{ M6 } & $\mathrm{a}_{\mathrm{u}}(45)$ & $-0,0158$ & $-0,0296$ \\
\hline & & & $b_{g}(48)$ & $-0,0332$ & $-0,0011$ \\
\hline & & & $a_{u}(52)$ & $-0,0126$ & $-0,0005$ \\
\hline & & & $b_{g}(55)$ & 0,0062 & 0,0124 \\
\hline & & & $a_{u}(56)$ & 0,0265 & 0,0178 \\
\hline & & & $b_{g}(57)$ & 0,0313 & 0,0068 \\
\hline & & & $b_{g}(58)$ & 0,0306 & 0,0044 \\
\hline & & & $\mathrm{au}_{\mathrm{u}}(59)$ & 0,0260 & 0,0165 \\
\hline & & & $a_{u}(60)$ & 0,0106 & 0,0173 \\
\hline & & & $\mathrm{PDI}_{\pi}$ & 0,0697 & 0,0439 \\
\hline & & & PDI & 0,0791 & 0.0521 \\
\hline \multirow[t]{10}{*}{ Pyrene } & \multirow[t]{10}{*}{$\mathrm{D}_{2 \mathrm{~h}}$} & \multirow[t]{10}{*}{ M7 } & $\mathrm{b}_{1 \mathrm{u}}(39)$ & $-0,0236$ & $-0,0254$ \\
\hline & & & $b_{2 g}(45)$ & $-0,0327$ & 0,0111 \\
\hline & & & $b_{3 g}(46)$ & 0,0132 & $-0,0057$ \\
\hline & & & $b_{1 u}(49)$ & 0,0155 & $-0,0082$ \\
\hline & & & $a_{u}(50)$ & 0,0338 & 0,0113 \\
\hline & & & $b_{1 u}(51)$ & 0,0047 & 0,0391 \\
\hline & & & $b_{2 g}(52)$ & 0,0291 & 0,0155 \\
\hline & & & $b_{39}(53)$ & 0,0199 & $-0,0031$ \\
\hline & & & $\mathrm{PDI}_{\pi}$ & 0,0600 & 0,0346 \\
\hline & & & PDI & 0,0691 & 0,0435 \\
\hline
\end{tabular}




\begin{tabular}{|c|c|c|c|c|c|}
\hline \multirow[t]{10}{*}{ Coronene } & \multirow[t]{10}{*}{$D_{6 h}$} & \multirow[t]{10}{*}{ M8 } & $\mathrm{a}_{2 \mathrm{u}}(55)$ & $-0,0144$ & $-0,0234$ \\
\hline & & & $\mathrm{e}_{1 \mathrm{~g}}(61,62)$ & 0,0196 & 0,0216 \\
\hline & & & $\mathrm{e}_{2 u}(68,69)$ & 0.0058 & -0.0054 \\
\hline & & & $\mathrm{a}_{2 \mathrm{u}}(72)$ & 0,0125 & $-0,0147$ \\
\hline & & & $b_{1 g}(73)$ & 0,0004 & 0,0000 \\
\hline & & & $b_{2 g}(74)$ & 0,0162 & 0,0029 \\
\hline & & & $\mathrm{e}_{1 \mathrm{~g}}(75,76)$ & 0,0255 & 0,0514 \\
\hline & & & $\mathrm{e}_{2 \mathrm{u}}(77,78)$ & 0,0177 & -0.0092 \\
\hline & & & $\mathrm{PDI}_{\pi}$ & 0,0441 & 0,0233 \\
\hline & & & PDI & 0,0531 & 0,0318 \\
\hline \multirow[t]{8}{*}{ Acenaphthalene } & \multirow[t]{8}{*}{$\mathrm{C}_{2 \mathrm{v}}$} & \multirow[t]{8}{*}{ M9 } & $\mathrm{b}_{1}(30)$ & -0.0358 & \\
\hline & & & $a_{2}(35)$ & $-0,0112$ & \\
\hline & & & $b_{1}(37)$ & 0,0189 & \\
\hline & & & $b_{1}(38)$ & 0,0409 & \\
\hline & & & $\mathrm{a}_{2}(39)$ & 0,0277 & \\
\hline & & & $b_{1}(40)$ & 0,0198 & \\
\hline & & & $\mathrm{PDI}_{\pi}$ & 0.0604 & \\
\hline & & & PDI & 0,0701 & \\
\hline \multirow[t]{9}{*}{ Pyracylene } & \multirow[t]{9}{*}{$\mathrm{D}_{2 \mathrm{~h}}$} & \multirow[t]{9}{*}{ M10 } & $\mathrm{b}_{1 \mathrm{u}}(34)$ & $-0,0353$ & \\
\hline & & & $b_{2 g}(38)$ & 0,0226 & \\
\hline & & & $b_{3 g}(41)$ & $-0,0109$ & \\
\hline & & & $b_{1 u}(43)$ & $-0,0063$ & \\
\hline & & & $\mathrm{a}_{\mathrm{u}}(44)$ & 0,0257 & \\
\hline & & & $b_{1 u}(45)$ & 0,0412 & \\
\hline & & & $b_{2 g}(46)$ & 0,0208 & \\
\hline & & & $\mathrm{PDI}_{\pi}$ & 0,0577 & \\
\hline & & & PDI & 0,0678 & \\
\hline \multirow[t]{8}{*}{ Indacene } & \multirow[t]{8}{*}{$\mathrm{D}_{2 \mathrm{~h}}$} & \multirow[t]{8}{*}{ M11 } & $\mathrm{b}_{1 \mathrm{u}}(29)$ & $-0,0269$ & \\
\hline & & & $b_{2 g}(35)$ & 0,0165 & \\
\hline & & & $b_{3 g}(37)$ & 0,0253 & \\
\hline & & & $\mathrm{b}_{1 \mathrm{u}}(38)$ & $-0,0071$ & \\
\hline & & & $\mathrm{au}_{\mathrm{u}}(39)$ & $-0,0121$ & \\
\hline & & & $b_{2 g}(40)$ & 0,0251 & \\
\hline & & & $\mathrm{PDI}_{\pi}$ & 0,0208 & \\
\hline & & & PDI & 0,0303 & \\
\hline
\end{tabular}




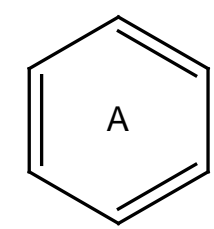

M1: Benzene

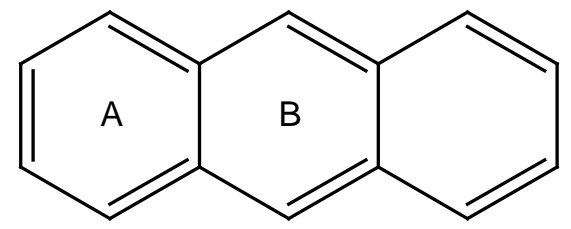

M3: Anthracene

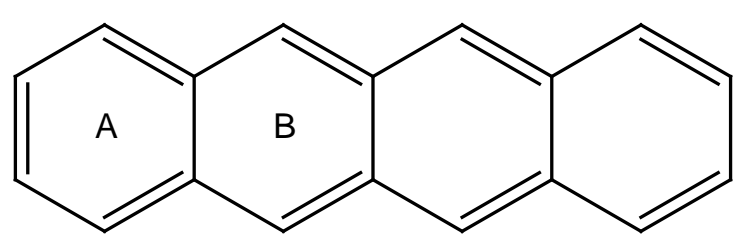

M5: Tetracene

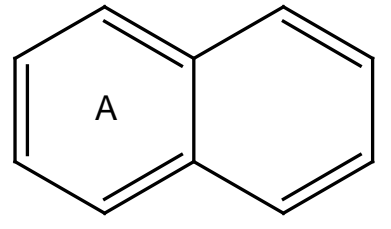

M2: Naphthalene

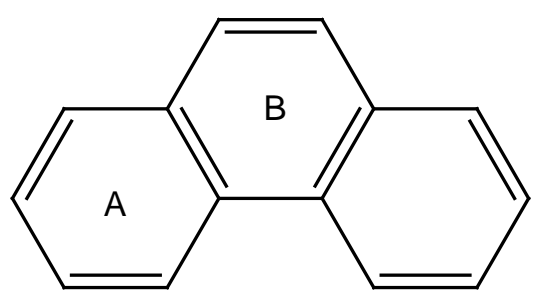

M4: Phenanthrene

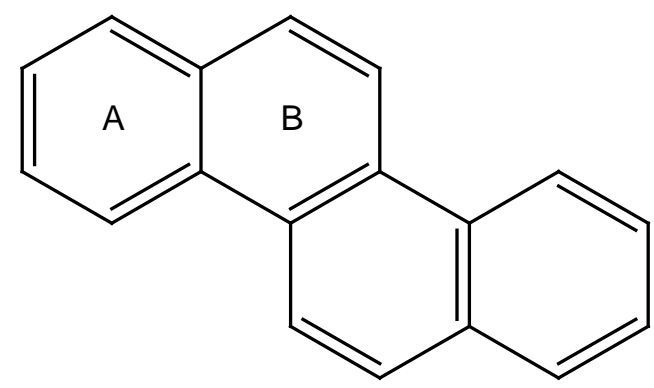

M6: Chrysene 


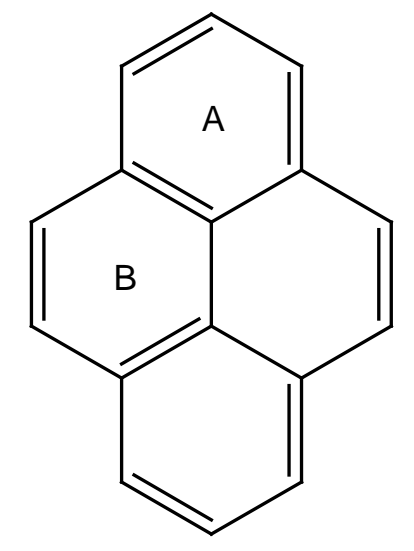

M7: Pyrene



M9: Acenaphthalene



M8: Coronene

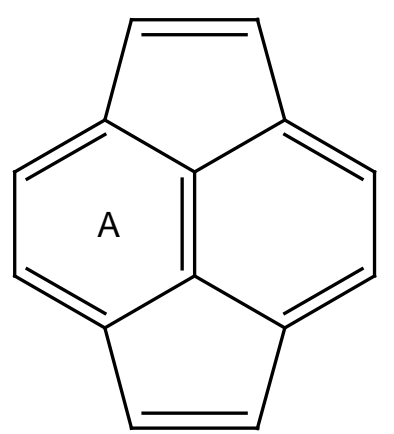

M10: Pyracylene

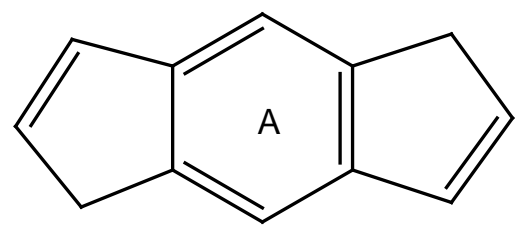

M11: Indacene

SCHEME 1 
Figure 1.

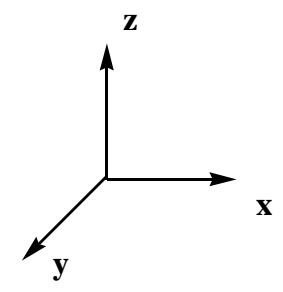

(a)



(c)

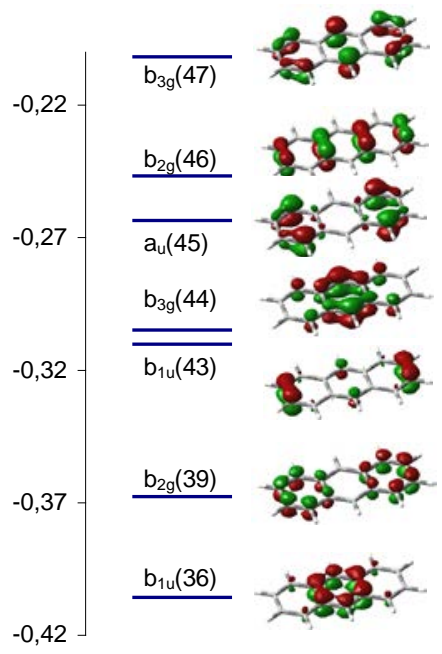

(b)

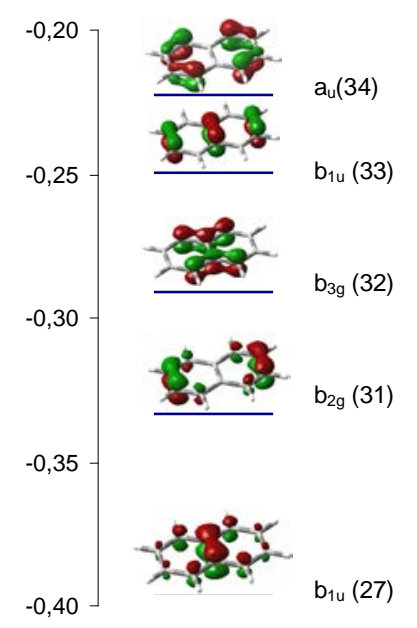

(d)

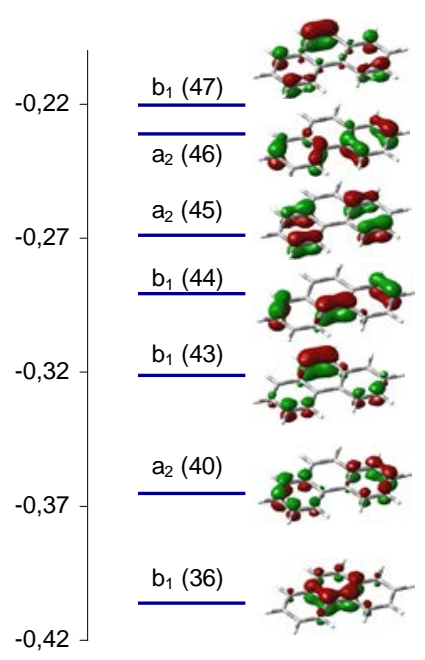


(e)

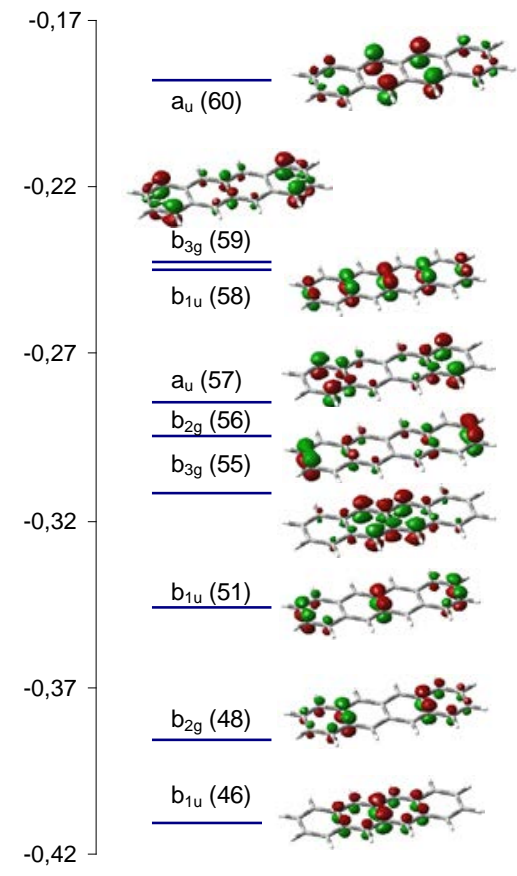

(g)

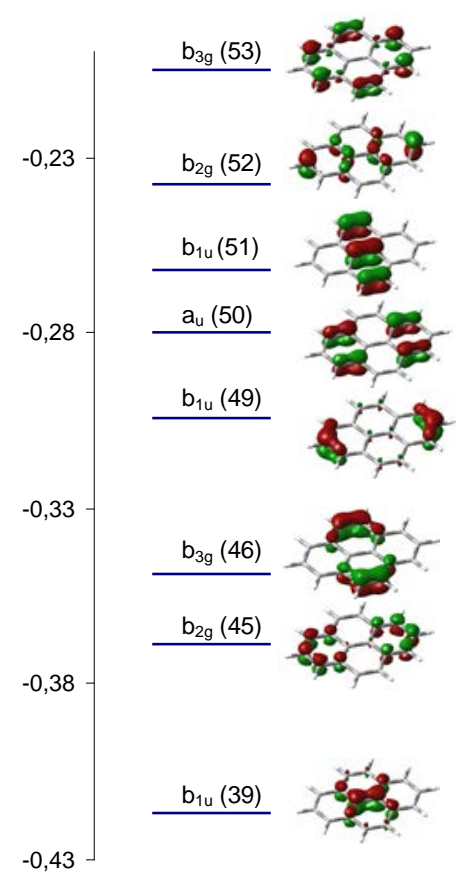

(f)

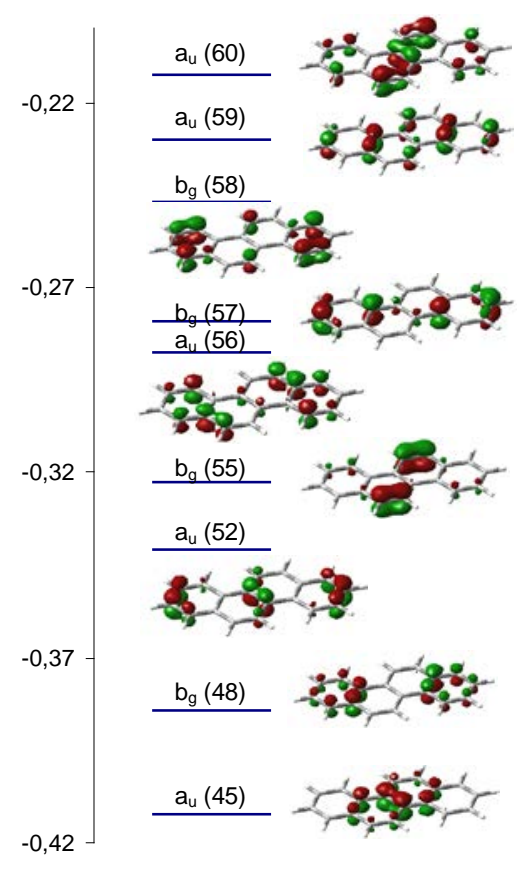

(h)

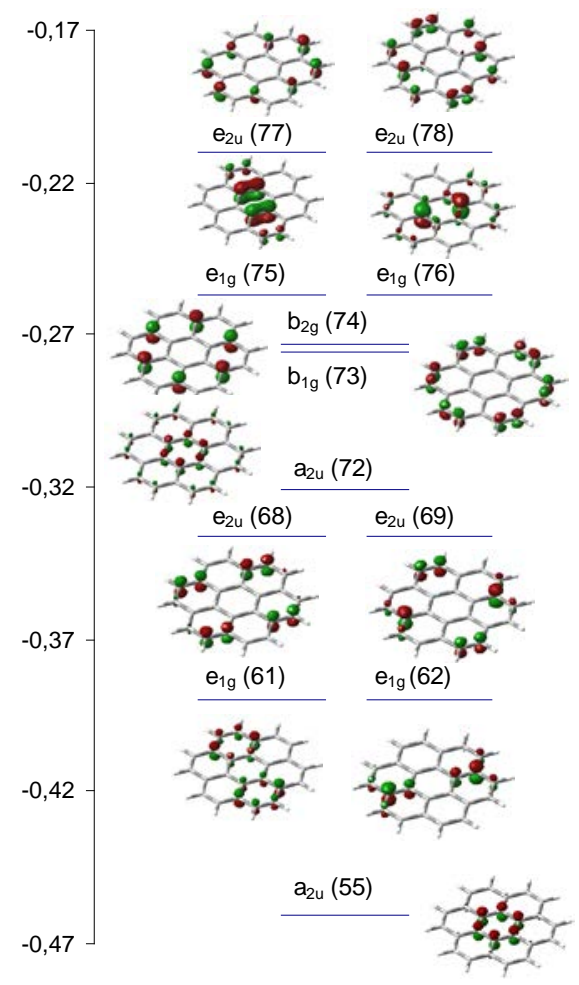


(i)

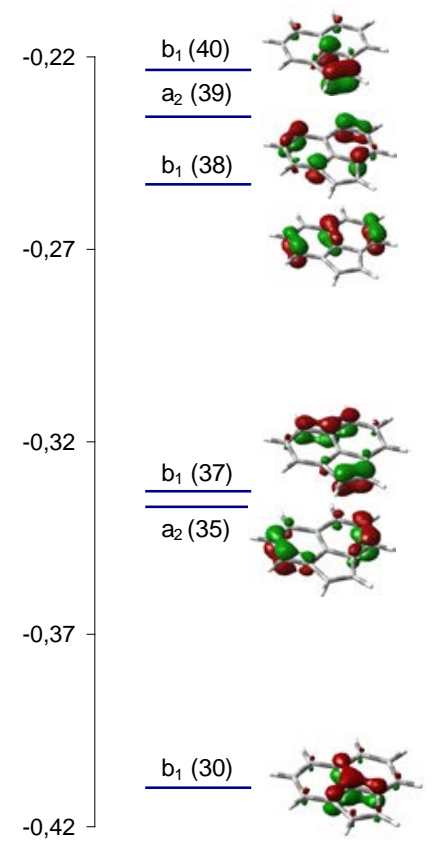

(k)

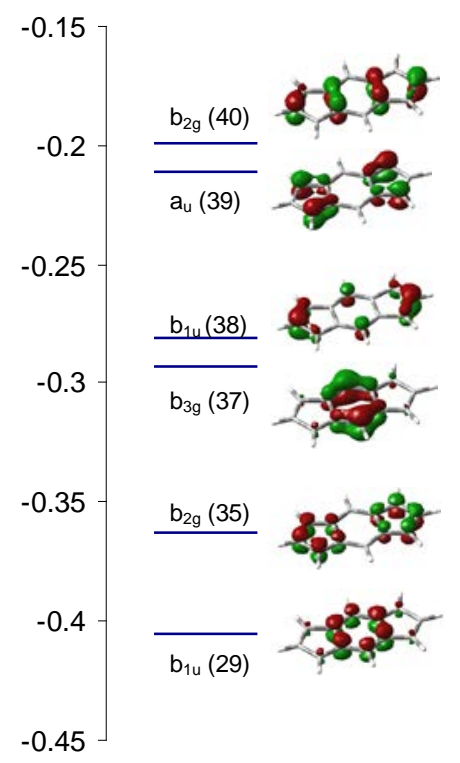

(j)

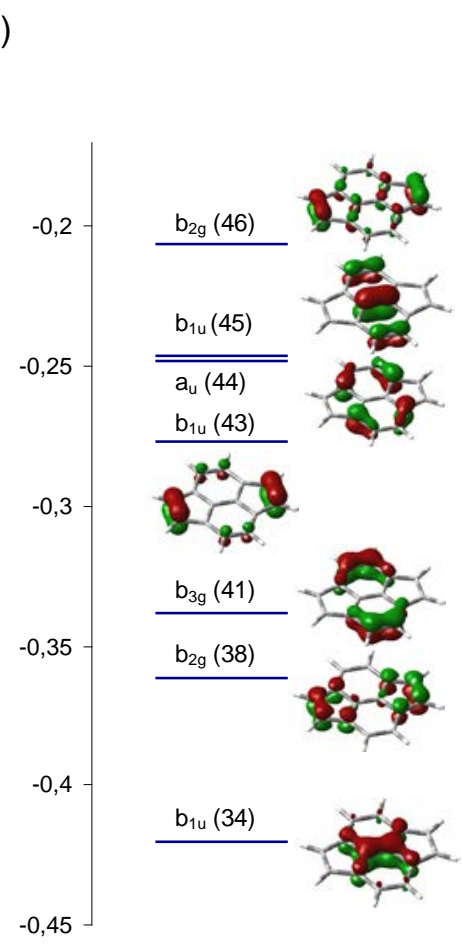

